\title{
HEMOCROMATOSE HEREDITÁRIA Relato de caso e revisão da literatura
}

\author{
Aécio Flávio Meirelles de SOUZA*, Roberto J. CARVALHO-FILHO** e \\ Júlio Fonseca CHEBLI*
}

RESUMO - Racional - A hemocromatose hereditária associada ao gene HFE é a doença hepática hereditária mais comum nas populações caucasianas e refere-se à associação de estoques aumentados de ferro com um dano tissular progressivo (como por exemplo, cirrose hepática, diabetes mellitus, cardiomiopatia), quando o diagnóstico e o tratamento são tardios. Objetivos - É apresentado o caso de uma paciente de 44 anos portadora de hemocromatose hereditária assintomática, cujo diagnóstico foi feito a partir da detecção casual de alterações na cinética do ferro. Apresenta-se, também, uma breve revisão da literatura sobre a doença. Conclusão - A existência de métodos diagnósticos capazes de identificar a doença antes que surjam suas complicações e a possibilidade de terapêutica efetiva que permita evitar as suas manifestações, tornam a hemocromatose hereditária entidade ideal para profilaxia primária, alterando completamente a sua história natural.

DESCRITORES - Hemocromatose. Sobrecarga de ferro.

\section{INTRODUÇÃO}

A primeira referência de hemocromatose data de 1865, na França, por Trousseau ${ }^{(30)}$. Quase 25 anos depois, em 1889, von Recklinghausen ${ }^{(32)}$, na Alemanha, foi o primeiro a utilizar o termo hemocromatose, pensando tratar-se de distúrbio hematológico que causava pigmentação cutânea. Entretanto, apenas em 1935, Sheldon deduziu que decorreria de distúrbio do metabolismo do ferro e que todas as manifestações da doença eram devidas à sobrecarga de depósito desse metal nos diversos órgãos ${ }^{(22)}$.

Atualmente, o termo hemocromatose se refere a doenças nas quais há um aumento progressivo nos estoques corpóreos de ferro, o que ocasiona sua deposição nas células parenquimatosas do coração, hipófise, gônadas, pâncreas, fígado e outros órgãos, com posterior dano estrutural e funcional destes ${ }^{(25)}$. Na ausência de terapêutica adequada e precoce, qual seja a remoção da sobrecarga orgânica de ferro, surgem as complicações da doença: insuficiência cardíaca, disfunção hipofisária e gonadal, diabetes mellitus, cirrose hepática e carcinoma hepatocelular, entre outras.

\section{DESCRIÇÃO DO CASO}

Em julho de 1999, uma mulher branca de 44 anos, natural e residente em Viçosa, MG, foi encaminhada ao serviço de Gastroenterologia do Hospital Universitário da Universidade Federal de Juiz de Fora, pelo achado fortuito de índice de saturação de transferrina (IST) e ferritina sérica (FS) aumentados. Encontrava-se completamente assintomática e o exame físico não demonstrava qualquer alteração clínica; apresentava história familiar positiva para diabetes mellitus (pai e mãe).

Os exames laboratoriais são apresentados na Tabela 1. O teste genético para hemocromatose por reação de cadeia de polimerase detectou homozigose para a mutação C282Y. Foi realizada biopsia hepática percutânea que revelou fígado de estrutura normal, no entanto com hepátocitos repletos de pigmento granuloso acastanhado. A avaliação semiquantitativa pelo Perls mostrou $+++/ 4+$, compatível com hemocromatose (Figuras 1 e 2).

\footnotetext{
Serviço de Gastroenterologia, Hospital Universitário, Universidade Federal de Juiz de Fora (UFJF).

* $\quad$ Professor Adjunto de Gastroenterologia da Faculdade de Medicina da UFJF.

** Médico Gastroenterologista.

Endereço para correspondência: Dr. Aécio Flávio Meirelles de Souza - Rua Renato Dias, 422 - Bairro Bom Pastor - 36021-610 - Juiz de Fora, MG. e-mail: meirelle@rural.com.br
} 
TABELA 1 - Achados laboratoriais

\begin{tabular}{lcc}
\hline & Antes do tratamento & Após o tratamento \\
\hline AST $(\mathrm{U} / \mathrm{L})$ & 28 & 34 \\
Bilirrubina $(\mu \mathrm{g} / \mathrm{dL})$ & 11 & 24 \\
Fe sérico $(\mu \mathrm{g} / \mathrm{dL})$ & 0,5 & - \\
CTLF $(\mu / \mathrm{dL}$ & 352 & 257 \\
IST $(\%)$ & 74 & 46,7 \\
FS $(\mathrm{ng} / \mathrm{mL})$ & 509 & 67 \\
ELISA anti-HCV & negativo & - \\
\hline
\end{tabular}

CTLF $=$ Capacidade total de ligação do ferro. IST $=$ indice de saturação de transferrina. $\mathrm{FS}=$ ferritina sérica

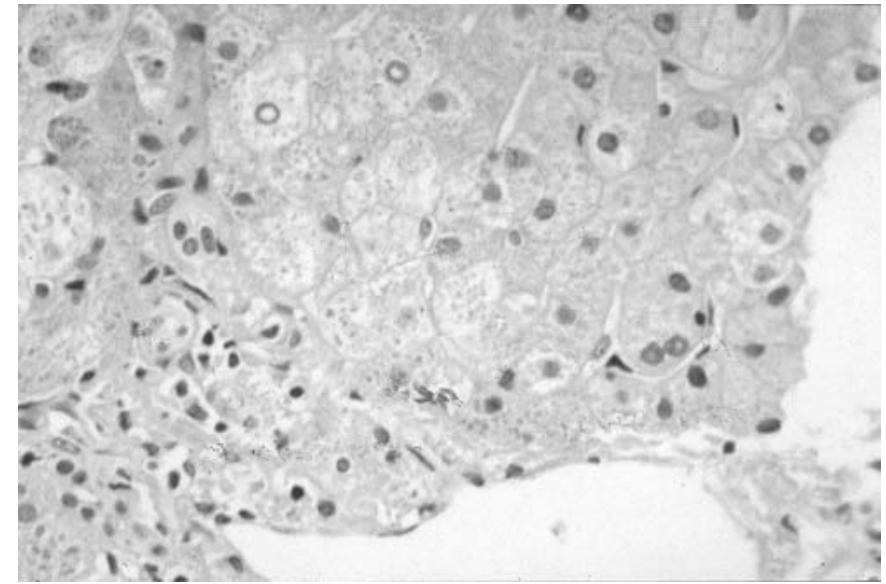

FIGURA 1 - Biopsia hepática mostrando depósitos de pigmento férrico no interior dos hepatócitos, mas não nas células de Kupffer. Magnificação x 200.

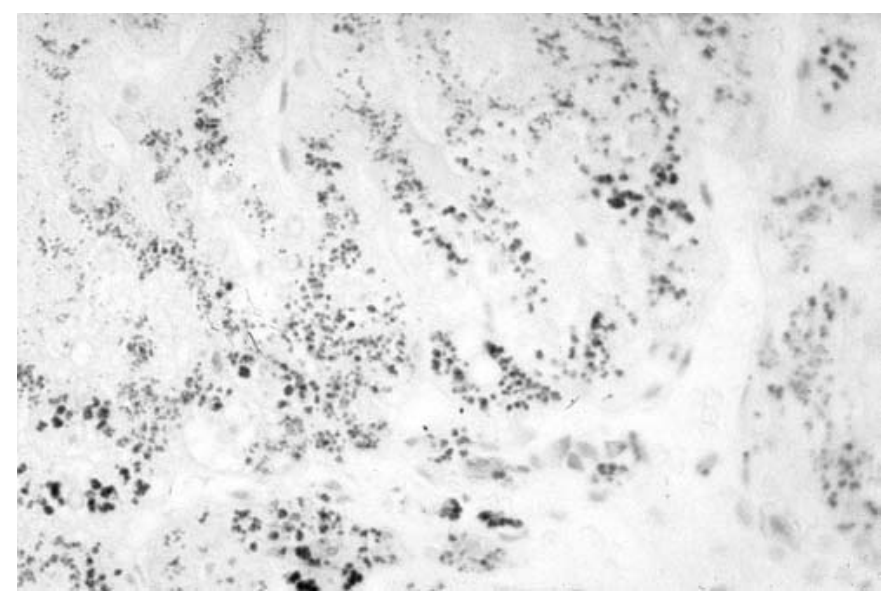

FIGURA 2 - Biopsia hepática após coloração de Perls (azul da Prússia), identificando o padrão característico da deposição de ferro. Magnificação x 200.
Em agosto de 1999, iniciou programa de flebotomias quinzenais com tolerabilidade satisfatória, que resultou em redução significativa dos depósitos de ferro (Tabela 1). A paciente permanece assintomática, sendo mantida, atualmente, sob programa de flebotomias a cada 3 meses.

\section{DISCUSSÃO / REVISÃO DA LITERATURA}

Em condições normais, o conteúdo total de ferro no organismo é muito estável: cerca de 4 a 5 g. Entretanto, nos pacientes sintomáticos com hemocromatose hereditária $(\mathrm{HH})$, o que geralmente ocorre entre os 40 e 60 anos de idade, os estoques do metal situam-se entre 20 e $40 \mathrm{~g}^{(18)}$, como conseqüência da hiperabsorção intestinal de ferro, muito acima das necessidades orgânicas ${ }^{(2)}$, a despeito de ingestão dietética com conteúdo normal do metal.

O mecanismo exato responsável por essa absorção aumentada de ferro não é ainda bem conhecido, aceitando-se que decorra da acentuação do transporte intestinal do metal dos enterócitos para a corrente sangüínea, provavelmente em conseqüência de programação equivocada das células duodenais superficiais, quando estas ainda se encontram nas criptas, fazendo com que elas captem ferro mais avidamente, como se houvesse uma deficiência orgânica do mesmo ${ }^{(26,27)}$.

Gera-se, portanto, deposição excessiva de ferro nas células parenquimatosas, em especial do fígado, pâncreas e coração, que acaba por estimular a peroxidação lipídica e produção de radicais livres, lesando-as e promovendo fibrose progressiva ${ }^{(18,22)}$ (Figura 3).

A HH é raramente diagnosticada antes dos 20 anos, quando os estoques de ferro ainda se encontram baixos, estando a maioria dos pacientes sintomáticos entre os 40 e 50 anos de idade. Embora o gene defeituoso seja igualmente distribuído entre homens e mulheres, a maioria dos estudos tem identificado mais homens do que mulheres na proporção de 4 a 10:1, o que pode ser explicado pelas "perdas fisiológicas" de ferro que elas apresentam através das menstruações e gestações ${ }^{(18,22)}$. $\mathrm{O}$ início da doença é insidioso, com sintomas inespecíficos que incluem astenia, letargia, fadiga, artralgias, perda da libido ou impotência sexual entre os homens e amenorréia entre as mulheres ${ }^{(3,18,26)}$. A hepatomegalia está 


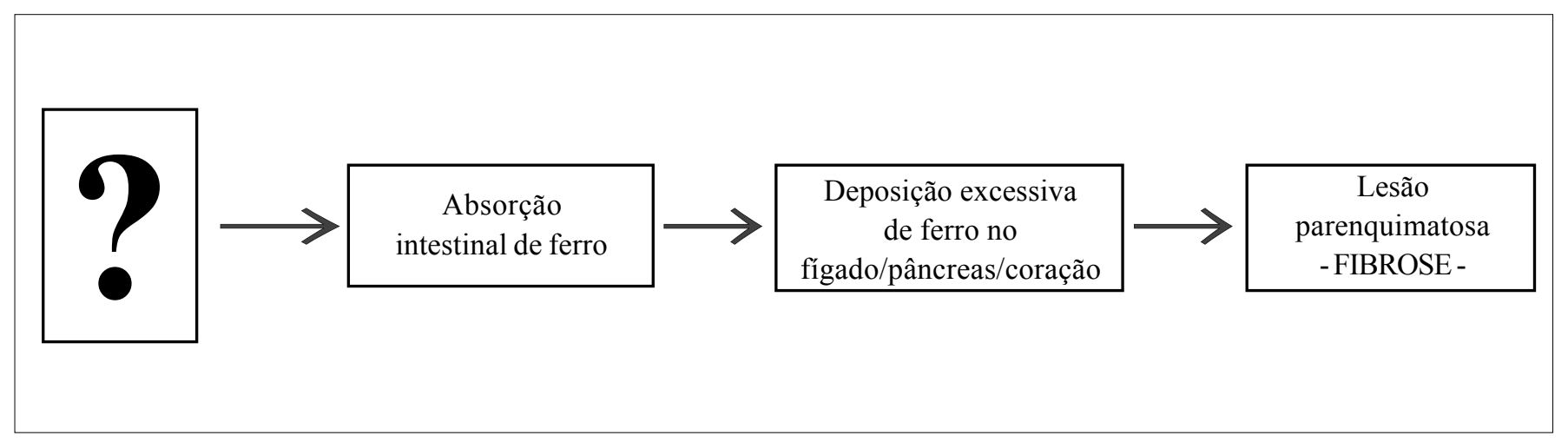

FIGURA 3 - Fisiopatologia da hemocromatose hereditária.

presente em cerca de $95 \%$ dos pacientes sintomáticos e geralmente precede o desenvolvimento de sintomas ou alterações dos testes de função hepática ${ }^{(3)}$. Com o decorrer do tempo, outros sintomas e sinais aparecem, tais como os que serão descritos a seguir.

\section{Dor abdominal}

Geralmente de caráter crônico, pode localizar-se em epigástrio e/ou quadrante superior direito, provavelmente em virtude da hepatomegalia e da distensão da cápsula hepática que se instalam. A dor abdominal como sintoma inicial tem sido identificada nas diversas séries com freqüências que variam entre $10 \%$ e $50 \%{ }^{(7)}$. Têm sido relatados alguns casos de dor abdominal intensa aguda associada a choque circulatório. Várias etiologias já foram implicadas, incluindo peritonite bacteriana e sepse por bactérias Gram-negativas ${ }^{(3)}$.

\section{Diabetes mellitus}

Embora depósitos de hemossiderina e fibrose estejam invariavelmente presentes no parênquima pancreático e que os maiores depósitos sejam encontrados nas células exócrinas, nenhuma evidência de insuficiência pancreática exócrina foi documentada. Por outro lado, $30 \%$ a $60 \%$ dos pacientes com $\mathrm{HH}$ avançada têm diabetes mellitus, sendo $70 \%$ insulino-dependentes. Tanto a resistência à insulina, quanto a diminuição da produção de insulina são encontrados ${ }^{(3)}$. A presença de diabetes piora o prognóstico(4).

\section{Outras anormalidades endócrinas}

A perda da libido e a atrofia testicular são comuns em indivíduos sintomáticos e podem anteceder outras manifestações clínicas, principalmente em jovens. Da mesma forma, outros sintomas de hipogonadismo como a amenorréia podem ocorrer antes que se altere a função hepática ${ }^{(3,26)}$.

\section{Manifestações cardíacas}

As manifestações cardíacas são encontradas em 20\% a 30\% dos doentes com HH. Em pacientes jovens, geralmente estão presentes no quadro inicial e constituem causa de morte freqüente entre $\operatorname{estes}^{(3)}$. A insuficiência cardíaca congestiva (ICC) com dilatação ventricular bilateral constitui clássico achado tardio, embora características restritivas tenham sido descritas. Arritmias também ocorrem, sendo as extrassístoles ventriculares as mais freqüentes. Entretanto, taquicardias ventricular e supraventricular, fibrilação ventricular e vários graus de bloqueios podem ser identificadas ${ }^{(3)}$. Mesmo nos casos avançados de ICC, pode-se obter boa resposta clínica após depleção de ferro através de programa de flebotomias em associação com deferoxamina ${ }^{(3,26)}$.

\section{Hiperpigmentação cutânea}

A hiperpigmentação cutânea está presente na maioria dos pacientes sintomáticos, mas está ausente nos estádios mais precoces do acúmulo de ferro. A pigmentação é, comumente, generalizada, embora possa ser mais acentuada na face, pescoço, faces extensoras dos antebraços, dorso das mãos, pernas, região genital e antigas cicatrizes ${ }^{(26)}$. A hiperpigmentação ocorre principalmente às custas da deposição de melanina na derme. Os depósitos de hemossiderina, quando presentes, são mais óbvios nas glândulas sudoríparas ${ }^{(3)}$.

\section{Artropatia hemocromatótica}

Ocorre em $20 \%$ a $70 \%$ dos indivíduos sintomáticos e pode representar a queixa inicial ${ }^{(26)}$. Deve-se sempre suspeitar de $\mathrm{HH}$ nos casos de sintomas/sinais de osteoartrite antes de 40 anos de idade. A artropatia não está associada à extensão ou duração da sobrecarga de ferro e pode surgir ou se agravar mesmo após a remoção do excesso dos estoques férricos ${ }^{(26)}$. É idêntica à osteoartrite degenerativa, exceto pelo achado freqüente $(50 \%)$ de deposição de pirofosfato cálcico 
(condrocalcinose $)^{(3,20)}$. A poliartropatia da $\mathrm{HH}$ tende a envolver as articulações metacarpofalangeanas (principalmente a segunda e terceira), interfalangeanas proximais, joelhos, punhos e articulações intervertebrais. Embora o envolvimento seja geralmente simétrico, pode ser unilateral ${ }^{(26)}$. As crises de pseudogota podem ser tratadas com antiinflamatórios não-hormonais ${ }^{(3)}$. A incidência e a gravidade aumentam com a idade, a despeito das flebotomias ${ }^{(3)}$.

\section{Sinais de insuficiência hepática crônica}

Nas fases mais tardias da doença, podem ocorrer esplenomegalia, edema de membros inferiores, ascite, icterícia e outros sinais de insuficiência hepática crônica, e hipertensão portal ${ }^{(7,22)}$. Sinais como eritema palmar, telangiectasias, rarefação de pêlos e ginecomastia são descritos, embora sejam menos comuns do que em cirroses de outras etiologias. As manifestações de hipertensão portal podem também ocorrer, mas são menos freqüentes do que na cirrose hepática alcoólica. A função hepática é, geralmente, bem conservada e os testes de função hepática podem ser normais, a despeito de grandes concentrações de ferro hepático e fibrose ${ }^{(26)}$.

\section{Predisposição a infecções}

Há maior predisposição a infecções, notadamente por Yersinia enterocolitica, Vibrio vulnificus, Listeria monocytogenes e Pasteurella pseudotuberculosis $^{(3,22)}$. Especula-se que a maior oferta de ferro não ligado à transferrina e possível disfunção dos linfócitos CD8 e macrófagos possam ter algum papel nesta predisposição $0^{(3,7)}$.

\section{DIAGNÓSTICO}

$\mathrm{O}$ diagnóstico de $\mathrm{HH}$ baseia-se na identificação de sinais e sintomas sugestivos da doença, na detecção de anormalidades bioquímicas do metabolismo do ferro e, finalmente, na comprovação da deposição acentuada do metal no fragmento de biopsia hepática e/ou por meio da realização de testes genéticos para a detecção de mutações da $\mathrm{HH}$ hereditária (C282Y e H63D).

A suspeita diagnóstica de HH deverá ser considerada em homens ou mulheres, em qualquer idade na vida adulta, quando estiverem presentes Astenia crônica imotivada e/ou Artralgia e/ou Aminotransferases elevadas sem motivo aparente, principalmente quando esta elevação for inferior a três vezes o limite superior da normalidade, caracterizando a "regra dos 3 As" ${ }^{\text {"(7). }}$. Uma vez identificado o paciente com suspeita clínica da doença, é necessário investigar os principais parâmetros do metabolismo do ferro, que são o IST e a FS.

O IST é o teste isolado mais sensível para a identificação fenotípica de homozigotos para $\mathrm{HH}^{(7,18,23)}$. É calculado a partir do quociente entre o ferro sérico e a capacidade total de ligação do ferro, multiplicado por
100. Seu valor normal situa-se entre $30 \%$ e $40 \%$, sendo geralmente maior que $60 \%$ nos homens e maior que $50 \%$ nas mulheres com $\mathrm{HH}$ clínica. É um índice mais estável que o ferro sérico e se altera mais precocemente, já que freqüentemente se eleva quando tais pacientes se encontram na adolescência ${ }^{(7,23)}$. Considera-se ser mais sensível para o diagnóstico do que a ferritina sérica, que apenas se torna elevada na presença de grandes acúmulos de ferro ${ }^{(7,23)}$, estando, em indivíduos normais, na faixa entre 10 e $300 \mu \mathrm{g} / \mathrm{L}$. Na $\mathrm{HH}$, principalmente em adolescentes $^{(9,27)}$, a ferritina sérica poderá estar normal, sendo importante não excluir o diagnóstico de $\mathrm{HH}$ antes de uma avaliação complementar.

A combinação de IST superior a $45 \%$ e ferritina sérica elevada em um indivíduo saudável tem sensibilidade de $93 \%$ para o diagnóstico de HH. Por outro lado, naqueles com mais de 35 anos, o valor preditivo negativo dos dois testes associados é de $97 \%^{(6)}$. Em um estudo australiano, a sensibilidade, especificidade e valor preditivo positivo de um IST acima de 50\% para a detecção de homozigose para C282Y foi, respectivamente, $94 \%, 96 \%$ e $6 \%{ }^{(23)}$.

$\mathrm{O}$ terceiro passo consiste em provar a existência de $\mathrm{HH}$ através de duas vias, na dependência da disponibilidade ou não de testes genéticos. A via confirmatória clássica para o diagnóstico de $\mathrm{HH}$ compreende a realização de biopsia hepática nos indivíduos com indícios clínicos e/ ou laboratoriais de sobrecarga de ferro, sendo essencial para: (1) confirmar a sobrecarga férrica; (2) identificar o padrão característico de distribuição periportal e hepatocítica dos depósitos de ferro; (3) promover avaliação semiquantitativa do excesso de ferro $^{(12)}$; (4) identificar a presença de fibrose ou cirrose; e (5) detectar lesões prémalignas potenciais, como por exemplo, focos livres de depósitos de ferro $^{(25,29)}$

O ferro hepático corável pela coloração de Perls ou "azul da Prússia" só assume importância quando acima de $++/ 4$ mantendo, entretanto, especificidade apenas relativa. Nesse caso, deve-se proceder à dosagem do metal no fígado ${ }^{(9)}$. Na doença não complicada, a fibrose e a cirrose comumente só são vistas quando as concentrações de ferro hepático excedem a $20.000 \mu \mathrm{g} / \mathrm{g}^{(9)} \mathrm{ou}$ acima de $500 \mu \mathrm{mol} / \mathrm{g} \mathrm{de}$ tecido $\operatorname{seco}^{(4)}$, exceto quando existam co-fatores, tal como o etilismo, onde pode haver dano hepático significativo em concentrações de ferro bem inferiores àquelas ${ }^{(14)}$. Nessa fase, um marcador importante de fibrose é a concentração sérica de colágeno tipo IV, que em níveis superiores a $115 \mathrm{ng} / \mathrm{mL}$ é 100\% sensível e 69\% específica na detecção de fibrose grave (grau 3) e cirrose em indivíduos com $\mathrm{HH}^{(13,19)}$.

$\mathrm{O}$ índice hepático de ferro (IHF) é outro importante exame na avaliação dos estados de sobrecarga de ferro. É calculado dividindo-se a concentração de ferro hepático (em $\mu \mathrm{mol} / \mathrm{g}$ ) pela idade do paciente em anos e se baseia no fato de que nos homozigotos para a mutação C282Y, a deposição tecidual vai aumentando proporcionalmente à idade do paciente, o que não ocorre com os heterozigotos e nas doenças que se acompanham de alguma sobrecarga secundária de ferro ${ }^{(14)}$. $\mathrm{Na}$ $\mathrm{HH}$, o IHF é geralmente maior que 1,9 ; nos pacientes com hepatopatia 
alcoólica é inferior a 1,5 e nos indivíduos normais situa-se entre 0,7 e 1,1. Para os indivíduos com valores entre 1,5 e 1,8 há necessidade de avaliação mais rigorosa, já que muitos hemocromatóticos jovens ou do sexo feminino têm índices dentro destes limites ${ }^{(22)}$. Vale ressaltar que $10 \%$ a $20 \%$ dos pacientes homozigóticos $\mathrm{C} 282 \mathrm{Y}$ com $\mathrm{HH}$ clínica possuem IHF inferior a $1,9^{(3,26)}$.

A estimativa da concentração hepática de ferro pode também ser feita através de tomografia computadorizada e ressonância nuclear magnética (RNM). Esse último exame, embora rotulado como método promissor, ainda carece com a tecnologia atual, de sensibilidade para o diagnóstico de concentrações não muito elevadas do metal ${ }^{(7)}$.

A nova via confirmatória é baseada na detecção da mutação $\mathrm{C} 282 \mathrm{Y}$ por técnica baseada em reação de cadeia de polimerase. A HH é doença autossômica recessiva, cujo gene responsável, identificado em 1996, foi chamado de HFE, localizando-se no braço curto do cromossomo $6^{(16)}$. Desde a sua descoberta, vários relatos têm confirmado a presença da mutação C282Y (gerada pela substituição da cisteína pela tirosina na posição 282) na maioria dos casos confirmados de $\mathrm{HH}^{(3,28)}$. Há evidências de que ela esteja restrita aos povos caucasianos de origem céltica (do norte da Europa), sendo que a maior prevalência de homozigose para aquela mutação é encontrada na Austrália ${ }^{(24)}$, enquanto que a menor prevalência localiza-se na Itália, onde apenas $64 \%$ dos pacientes com HH clínica a possuem em homozigose ${ }^{(2)}$. A prevalência de homozigotos $\mathrm{C} 282 \mathrm{Y}$ é de aproximadamente 1:220 e de heterozigotos é de até $1: 10^{(18)}$. Estima-se, por exemplo, que existam nos Estados Unidos cerca de 600 mil homozigotos e 27 milhões de heterozigotos. A discrepância evidente entre prevalência de homozigose C282Y e HH clínica expressa a penetração incompleta daquela mutação, assumindo importância outros fatores tais como os dietéticos e culturais, colaborando na expressão fenotípica desta alteração genética ${ }^{(5)}$. Os heterozigotos para a mutação $\mathrm{C} 282 \mathrm{Y}$ podem ter marcadores bioquímicos de acúmulo de ferro, mas não desenvolvem sobrecarga clinicamente significativa ${ }^{(4,8)}$. Vários outros polimorfismos foram estudados, mas seu significado clínico ainda é desconhecido. Pelo menos uma destas outras mutações, a chamada H63D (histidina no lugar de aspartato na posição 63) é provavelmente deletéria quando em heterozigose composta com a mutação $\mathrm{C} 282 \mathrm{Y}^{(1,6)}$.

A genotipagem para a mutação $\mathrm{C} 282 \mathrm{Y}$ é teste útil no diagnóstico de $\mathrm{HH}$ na prática clínica, com sensibilidade de cerca de $90 \%$ e especificidade de $100 \%{ }^{(17)}$. Quando é determinada a homozigose para a mutação C282Y, isto é, C282Y +/+, é feito o diagnóstico de $\mathrm{HH}$, restando-nos avaliar o grau de excesso de ferro; além dos achados clínicos sugestivos, esta avaliação é essencialmente baseada no grau de hiperferritinemia e, se disponível, em dados de RNM (hipossinal hepático em $\mathrm{T} 2)^{(7)}$.

Desta forma, a maior mudança estratégica entre as duas vias confirmatórias no diagnóstico da HH é a realização de biopsia hepática, na nova via, mais com objetivos prognósticos do que diagnósticos. A biopsia hepática ficaria, então, restrita aos casos nos quais houvesse suspeita significativa de uma sobrecarga de ferro suficientemente grande que possibilitasse a existência de dano hepático: fibrose ou mesmo cirrose ${ }^{(7)}$. Entretanto, há alguma discussão quanto aos limites daqueles sinais preditivos de dano hepático. Parece haver consenso quanto aos valores de ferritina sérica superiores a $1.500 \mu \mathrm{g} / \mathrm{L}$, principalmente quando há hepatomegalia e hipertransaminasemia ${ }^{(1,7)}$

Os exames complementares utilizados na avaliação da $\mathrm{HH}$ e os valores de referência estão descritos na Tabela 2 .

Um algoritmo para o rastreamento de $\mathrm{HH}$ associada ao gene HFE em pacientes individuais, familiares de pacientes sabidamente portadores de $\mathrm{HH}$ associada ao HFE e na população geral é demonstrado na Figura 4.

TABELA 2 - Exames complementares úteis na suspeita de hemocromatose

\begin{tabular}{lcc}
\hline \multicolumn{1}{c}{ Exames } & Valores normais & Hemocromatose \\
\hline$\cdot$ IST* $\%)$ & 20 a 40 & $45-100$ \\
$\cdot$ Ferritina sérica $(\mathrm{ng} / \mathrm{mL}):$ & 25 a 400 & 500 a 3.000 \\
-Homens & 11 a 120 & 250 a 400 \\
-Mulheres & 0 a ++ & +++ a ++++ \\
$\cdot$ Ferro hepático corável (Perls) & 300 a 1.800 & 3.000 a 40.000 \\
$-\mu \mathrm{g} / \mathrm{g}$ tecido seco & 5 a 27 & $>80$ \\
$-\mu$ gmol/g tecido seco & $<1,1$ & $>1,9$ \\
- Índice de ferro hepático & & $>115 \mathrm{ng} / \mathrm{mL}$ \\
$(\mu$ mol/g tecido seco $\div$ idade em anos) & $<115 \mathrm{ng} / \mathrm{mL}$ & \\
\hline
\end{tabular}

*IST = Índice de saturação de transferrina 


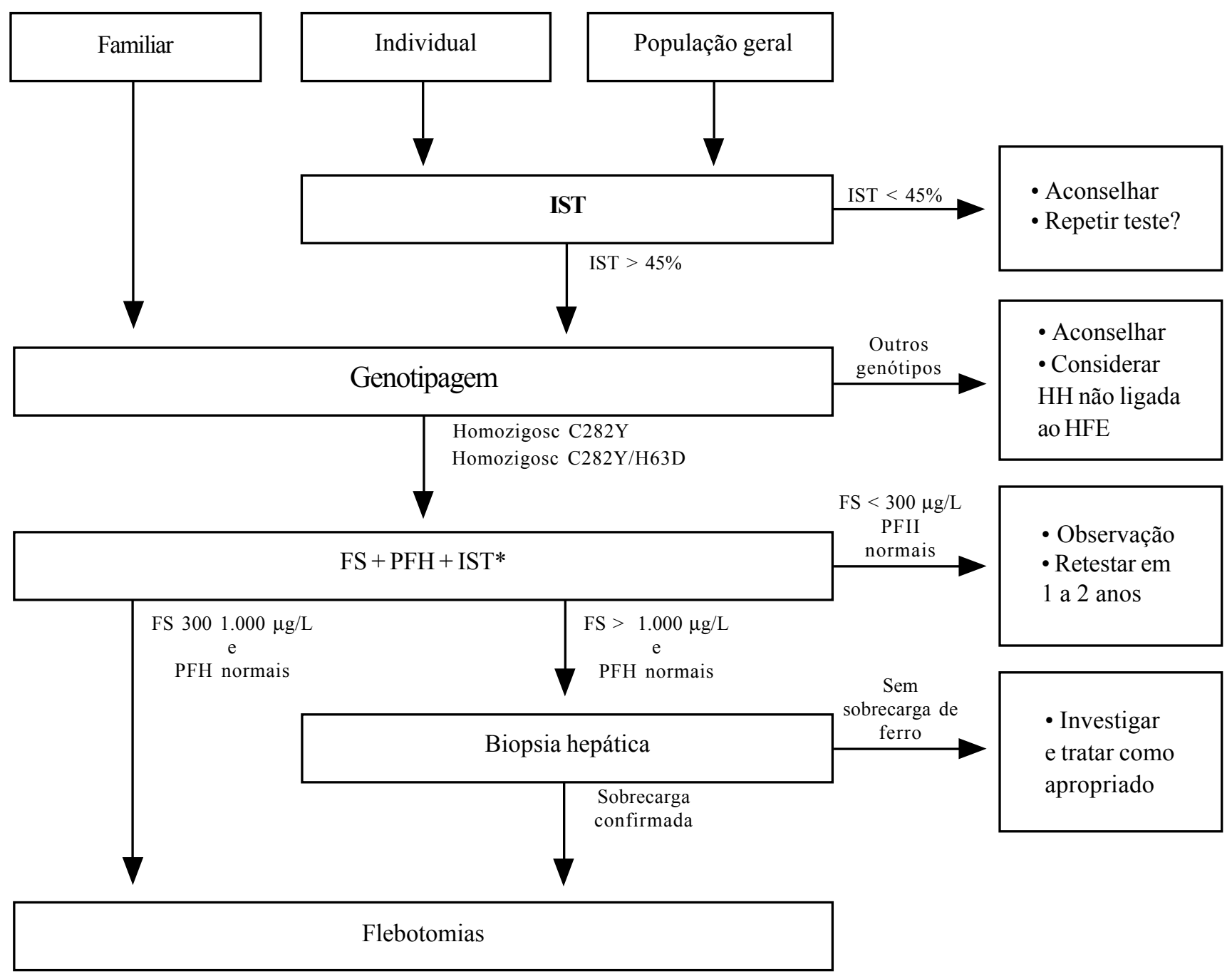

FIGURA 4 - Algoritmo para o rastreamento de HH associada ao gene HFE em pacientes individuais, familiares de pacientes individuais, familiares de pacientes sabidamente portadores de HH associada ao HFE e na população geral. (Modificado de Powell et al. ${ }^{(27)}$. IST = índice de saturação de transferrina. FS = ferritina sérica. PFH = provas de função hepática. ${ }^{*}=$ se não realizado anteriormente.

\section{TRATAMENTO}

O consenso internacional sobre HH organizado pela Associação Européia para o Estudo do Fígado ${ }^{(1)}$ não indica a adoção de dieta estritamente pobre em ferro, mas recomenda que tais pacientes devam evitar alimentos com alto teor do metal (tais como carne vermelha e fígado - ricas fontes de ferro ligado ao heme), suplementos de ferro e vitamina $C$ (que aumenta a absorção intestinal de ferro), bebidas alcoólicas (que podem acelerar o dano hepático) e frutos do mar (principalmente ostras cruas), responsáveis por casos de infecções fatais geradas por sua contaminação com Vibrio vulnificus em pacientes com $\mathrm{HH}^{(6)}$.

A remoção de ferro por venissecção ainda é a principal modalidade terapêutica para a $\mathrm{HH}$, com indícios evidentes de melhora da sobrevida em vários estudos ${ }^{(6,7,14,18,22,25)}$. O tratamento visa apenas os homozigotos e tem por finalidade esgotar os estoques corpóreos aumentados do metal, procurando levá-los aos seus níveis normais. A maioria dos autores preconiza programa semanal ou quinzenal de flebotomias de $500 \mathrm{~mL}$ (perda de $250 \mathrm{mg}$ de ferro), de acordo com a tolerância de cada indivíduo (menor nos indivíduos 
idosos), com duração de alguns meses até 2 a 3 anos, conforme a precocidade do diagnóstico e do tratamento, até que os estoques em excesso de ferro sejam esgotados. É aconselhável a dosagem de ferritina sérica e IST a cada 2 a 3 meses ou a cada 1 a 2 g de ferro removido, a fim de acompanhar o retorno ao normal dos estoques férricos. No início, a ferritina pode oscilar muito, para em seguida cair progressivamente. Já o IST não é bom parâmetro para avaliação durante o programa de sangrias, pois tem tendência a se manter elevado até que os estoques se aproximem dos limites inferiores da normalidade ${ }^{(30)}$. Quando isto ocorre, a ferritina apresenta-se abaixo de 30 a $50 \mathrm{ng} / \mathrm{mL}$, o IST é inferior a 50\%. A hemoglobina deverá ser dosada antes de cada sangria, idealmente situando-se em torno de $11 \mathrm{~g} / \mathrm{dL}$, sem tendência a se elevar de imediato com a suspensão do tratamento. Quando estes parâmetros são alcançados, o objetivo passa a ser o de evitar o reacúmulo de ferro, sendo suficiente, em geral, uma sangria de $500 \mathrm{~mL}$ a cada 3 a 4 meses por toda a vida, embora alguns indivíduos possam requerê-las em intervalos mais $\operatorname{curtos}^{(4,6,7,14,18,22,25)}$. O sangue retirado poderá ser utilizado em bancos de sangue, desde que sejam excluídas as doenças hemotransmissíveis potenciais ${ }^{(3)}$. Não há consenso sobre o limite de idade a partir do qual estaria indicado o início do programa de flebotomias em indivíduos jovens assintomáticos. Entretanto, existe tendência a propor a terapia em pacientes a partir dos 18 anos de idade $^{(1)}$.

A deferoxamina é um agente quelante do ferro introduzido na prática clínica há mais de 20 anos. Entretanto, não é recomendada habitualmente no tratamento da HH já que é droga de alto custo, de administração trabalhosa (geralmente como infusão subcutânea contínua em período de 12 horas por 4 a 6 dias por semana através de bomba especial portátil) e, sozinha, mostrou-se praticamente ineficaz neste tipo de doença, pois possibilita a excreção diária de apenas 20 a $90 \mathrm{mg}$ de ferro ${ }^{(11,14,22)}$. Além disso, existem complicações potenciais com o uso crônico da deferoxamina tais como infecções por Yersinia $s p$, lesões retinianas e de nervo acústico ${ }^{(31)}$. Ela poderá ser útil, todavia, como coadjuvante das flebotomias em alguns casos de $\mathrm{HH}$ com cardiopatia ou naqueles indivíduos que não toleram o programa de sangrias ${ }^{(14,22)}$. Outra opção resulta no emprego do deferiprone, um quelante oral usado nas sobrecargas de ferro relacionadas às anemias hemolíticas, com resultados controversos ${ }^{(21)}$, esperando-se que, num futuro próximo, surjam outros fármacos mais eficazes e disponíveis para o tratamento da $\mathrm{HH}$.

O tratamento não reverte a cirrose já estabelecida, mas proporciona nítida melhora clínica e laboratorial da disfunção hepática presente. Reduz também a dependência à insulina dos pacientes com diabetes mellitus, melhora a pigmentação anormal da pele, os distúrbios cardíacos determinados pela síndrome, o mal estar geral, a astenia e as dores abdominais, se presentes ${ }^{(1,6)}$. Por outro lado, as flebotomias não melhoram o hipogonadismo e suas conseqüências, não impedem o aparecimento e a progressão da artropatia e não impedem o surgimento de carcinoma hepatocelular ( $\mathrm{CHC}$ ), embora diminuam sua incidência ${ }^{(7,14)}$.

\section{PROGNÓSTICO}

O prognóstico da $\mathrm{HH}$ parece depender diretamente da quantidade (e, provavelmente, da duração) do acúmulo de ferro. Pacientes que são depletados durante os primeiros 18 meses de tratamento têm melhor prognóstico ${ }^{(26)}$. A expectativa de vida é normal se as flebotomias forem iniciadas antes do surgimento de cirrose e, mesmo nos cirróticos, a taxa de sobrevida em 10 anos, após normalização dos estoques de ferro, é de $80 \%$, bem superior àquela de outras formas de cirrose hepática ${ }^{(7)}$. O prognóstico é mais grave quando há cirrose hepática ao diagnóstico ou diabetes mellitus, mas não é influenciado pelo sexo ou pela existência de $\operatorname{artropatia}^{(7,25)}$

O transplante ortotópico de fígado (TOF) tem sido recomendado para os casos de cirrose descompensada, sendo importante ressaltar que vários estudos têm demonstrado que nesses pacientes a mortalidade pós-transplante é muito maior que a observada em outros tipos de cirrose, provavelmente em decorrência de cardiopatias concomitantes e intercorrências infecciosas, com sobrevida em 1 ano após TOF de cerca de $50 \%$, bem abaixo de 80 a $90 \%$, taxas observadas nas demais hepatopatias crônicas ${ }^{(15)}$.

Existem várias evidências provenientes de estudos experimentais e em humanos que sustentam o papel carcinogênico do ferro, seja em sua forma livre ou ligado à transferrina ${ }^{(11)}$. Assim, o risco de morte por $\mathrm{CHC}$ em um indivíduo com HH é 100 vezes maior que o da população geral( ${ }^{(25)}$, vindo a diagnosticar-se esse tipo de neoplasia em até 30\% dos que já se apresentam cirróticos com a doença ${ }^{(26)}$ e, em muitos casos, surgindo vários anos após a depleção adequada dos estoques de ferro por flebotomias ${ }^{(25)}$. Deve-se também ressaltar que essa evolução pode ser observada entre não-cirróticos ${ }^{(20)}$, sendo que a sobrecarga de ferro parece contribuir para o desenvolvimento desse tumor em indivíduos com cirrose hepática causada por infecção crônica pelo vírus da hepatite $\mathrm{C}^{(10)}$.

$\mathrm{O}$ rastreamento ideal de $\mathrm{CHC}$ em portadores de $\mathrm{HH}$ ainda está por ser definido. Entretanto, estudos preliminares prospectivos demonstraram que devam ser avaliados a cada semestre com ultrasonografia abdominal e dosagem de alfa-fetoproteína, medidas capazes de detectar tumores de até $1 \mathrm{~cm}$ de diâmetro ${ }^{(29)}$, estratégia somente indicada para pacientes cirróticos ${ }^{(22)}$.

Este relato de caso assume importância para alguns aspectos: (1) detecção da $\mathrm{HH}$ em pacientes do sexo feminino e de forma assintomática, em fase pré-menopausa; (2) história familiar de diabetes mellitus, o que sugere ocorrência de outros casos entre ascendentes; (3) o alerta para caracterização de sinais bioquímicos de distúrbios do metabolismo do ferro, em pacientes com valores 
séricos normais de aminotransferases; (4) comprovação da mutação C282Y, com biopsia mostrando fígado estruturalmente normal, porém com depósitos de ferro em excesso em hepatócitos e não nas células de Kupffer; (5) pronta intervenção terapêutica com benefícios comprovados através dos achados laboratoriais póstratamento, certamente impedindo que possa haver evolução para fibrose, cirrose e até mesmo $\mathrm{CHC}$, a mais longo prazo.

\section{AGRADECIMENTOS}

Nossos sinceros agradecimentos aos colegas que colaboraram de maneira inestimável para a publicação deste artigo: Pedro D. Gaburri, Lincoln E.V.V.C. Ferreira, Kátia V.B.D. Barbosa, Karla O. Cimino, Fernando A. Lucca, Raimunda Violante Campos de Assis e Sandra Márcia Carvalho R. Costa.

Souza AFM, Carvalho-Filho RJ, Chebli JF. Hereditary hemochromatosis. Case report and review of the literature. Arq Gastroenterol 2001;38(3):194-202.

ABSTRACT - Background - HFE-associated hemochromatosis is one of the most common inherited liver disease in Caucasian populations and refers to the association of increased iron stores with tissue damage (e.g., cirrhosis, diabetes, cardiomyopathy), which is progressive when diagnosis and treatment are delayed. Aims - Description of a case of hereditary hemochromatosis in an asymptomatic 44-years-old patient, whose diagnosis was made through casual identification of abnormal iron markers. We will also present a brief review of the literature about the topic. Conclusions - Hereditary hemochromatosis is an ideal disease for primary prevention since the disease can be detected well before serious complications develop. This intervention has been shown to prevent the manifestations of the disease, altering its natural history.

HEADINGS - Hemochromatosis. Iron overload.

\section{REFERÊNCIAS BIBLIOGRÁFICAS}

1. Adams P, Brissot P, Powell LW. EASL International Consensus Conference on Haemochromatosis. J Hepatol 2000;33:485-504.

2. Andrews NC. Disorders of iron metabolism. N Engl J Med 1999;341:1986-98

3. Bacon BR, Tavill AS. Hemochromatosis and the iron overload syndromes. In: Zakim D, Boyer TD, editors. Hepatology - a textbook of liver disease. 3.ed. Philadelphia: W.B. Saunders; 1997. v.2, p.1439-72

4. Bacon BR, Britton RS. Hereditary hemochromatosis. In: Feldman M, Scharschmidt $\mathrm{BF}$, Sleisenger MH, editors. Sleisenger \& Fordtran's gastrointestinal and live disease - pathophysiology/diagnosis/management. 6. ed. Philadelphia: W.B. Saunders; 1998. p.1097-103.

5. Bhavnani M, Lloyd D, Bhattacharyya A, Marples J, Elton P, Worwood M. Screening for genetic haemochromatosis in blood samples with raised alanine aminotransferasis. Gut 2000;46:707-10

6. Bothwell TH, MacPhail AP. Hereditary hemochromatosis: etiologic, pathologic, and clinical aspects. Sem Hematol 1988;35:55-71.

7. Brissot P, Moirand R, Guyader D, Loréal O, Turlin B, Deugnier Y. Hemochromatosis after the gene discovery: revisiting the diagnostic strategy. J Hepatol 1998;28:14-8.

8. Bulaj ZJ, Griffen LM, Jorde LB, Edwards CQ, Kushner JP. Clinical and biochemical abnormalities in people heterozygous for hemochromatosis. N Engl J Med 1996;335:1799-805.

9. Catterson PR, Summerfield GP, Beesley JF. Interpretation of iron studies in adolescent haemochromatosis. Clin Lab Haematol 1999;21:129-31.

10. Chapoutot C, Esslimani M, Joomaye Z, Ramos J, Perney P, Laurent C, FabbroPeray P, Larrey D, Domergue J, Blanc F. Liver iron excess in patients with hepatocellular carcinoma developed on viral C cirrhosis. Gut 2000;46:711-4.

11. Deugnier Y, Turlin B, Loréal O. Iron and neoplasia. J Hepatol 1998;28:21-5.

12. El-Serag HB, Inadomi JM, Kowdley KV. Screening for hereditary hemochromatosis in siblings and children of affected patients. A costeffectiveness analysis. Ann Intern Med 2000;132:261-9.

13. Fairbanks VF, Baldus WP. Iron overload (hemochromatosis). In: Bennett JC, Plum F, editors. Cecil textbook of medicine. 20.ed. Philadelphia: W.B. Saunders; 1996. p.1132-5.
14. Fargion S, Mandelli C, Piperno A, Cesana B, Fracanzani AL, Fraquelli M. Survival and prognostic factors in 212 Italian patients with genetic hemochromatosis Hepatology 1992;15:655-9.

15. Farrell FJ, Nguyen M, Woodley S. Outcome of liver transplantation in patients with hemochromatosis. Hepatology 1994;20:404.

16. Feder JN, Gnirke A, Thomas W. A novel MHC class-I like gene is mutated in patients with hereditary haemochromatosis. Nat Genet 1996;13:399-408.

17. Florkowsky CM, George PM, Willis JA. Haemochromatosis gene mutations Cys282Tyr and His63Asp are not increased in type 2 diabetic patients compared with the Canterbury (New Zealand) general population. Diabetes Res Clin Pract 1999;43:199-203.

18. Galizzi Filho J, Andrade MO. Doença de Wilson e hemocromatose. In: Parise ER, Porta G, editores. Manual de diagnóstico e tratamento das doenças hepáticas - no paciente adulto e pediátrico. São Paulo: 1999. p.145-57.

19. George DK, Rann GA, Walker NI. Elevated serum type IV collagen: a sensitive indicator of the presence of cirrhosis in haemochromatosis. J Hepatol 1999;31:4752.

20. Goh J, Callagy G, McEntee G. Hepatocellular carcinoma arising in the absence of cirrhosis in genetic haemochromatosis: three case reports and review of literature. Eur J Gastroenterol Hepatol 1999;11:915-9.

21. Kowdley KV, Kaplan MM. Iron-chelation therapy with oral deferiprone - toxicity or lack of efficacy? N Engl J Med 1998;339:468-9.

22. Niederau C, Erhardt A, Häussinger D, Strohmeyer G. Haemochromatosis and the liver. J Hepatol 1999;30:6-11.

23. Olynyk JK, Cullen DJ, Aquilia S, Rossi E, Summerville L, Powell LW. A population-based study of the clinical expression of the hemochromatosis gene. N Engl J Med 1999;341:755-7.

24. Pietrangelo A, Montosi G, Totaro A, Garuti C, Conte D, Cassanelli S, Fraquelli M, Sardini C, Vasta F, Gasparini P. Hereditary hemochromatosis in adults without pathogenic mutations in the hemochromatosis gene. N Eng J Med 1999;341:755-7.

25. Powell LW. Genetic diagnosis of hemochromatosis: implications for prophylaxis and treatment. In: Arroyo V, Bosch J, Bruguera M, editors. Therapy in liver diseases. Barcelona: Masson; 1997. p.391-404.

26. Powell LW, Leggett BA, Crawford DHG. Hemochromatosis and other iron storage disorders. In: Schiff ER, Sorrell MF, Maddrey WC, editors. Schiff's diseases of the liver. 8.ed. Philadelphia: Lippincott/Williams \& Wilkins; 1999. v.2, p.1107-30. 
27. Powell LW, Subramaniam N, Yapp TR. Haemochromatosis in the new millennium. J Hepatol 1999;32(suppl.1):48-62.

28. Rossi E, Henderson S, Chin C. Genotyping as a diagnostic aid in genetic haemochromatosis. J Gastroenterol Hepatol 1999;14:427-30.

29. Tavill AS. Clinical implications of the hemochromatosis gene. N Engl J Med 1999;341:755-7.

30. Trousseau A. Glycosurie, diabete sucre. In: Anonymous clinique medicale de l'Hotel-Dieu de Paris. 2.ed. Paris: Bailliere; 1865. p.663.
31. Ten Kate J, Marell K, Huizinga R. Iron saturation of ferritin in the course of phlebotomy treatment in patients with haemochromatosis. Clin Chem Lab Med 1999;37:827-30.

32. von Recklinghausen FD. Uber Hamochromatose. Tagebl Versamml Natur Arzte Heidelberg 1889;62:324.

Recebido em 11/1/2001. Aprovado em 19/4/2001. 